\title{
Open access policy at Reviews in Health Care
}

Silvia Maina ${ }^{1}$

Editor, SEEd Medical Publishers

According to the Budapest Open Access Initiative, open access means «immediate, free availability on the public internet, permitting any users to read, download, copy, distribute, print, search or link to the full text of these articles, crawl them for indexing, pass them as data to software or use them for any other lawful purpose».

Health care literature dissemination is part of the core mission of Reviews in Health Care. That's why, since its launch in October 2010, Reviews in Health Care has been willing to develop an open access model.

We are now very pleased to announce to our authors and readers that every article published in the journal is freely accessible on the Web, immediately on publication.

To this purpose, we developed a new website (http://journals.edizioniseed.it/index.php/rho, based on the Open Journal Systems journal management) where all the articles are freely available in html (a registration is required).

We believe that, at a time of tight research budgets, it is not reasonable to expect Universities or authors to pay thousands of dollars to publish an article. Therefore, Reviews in Health Care offers the authors the opportunity to publish their papers at no cost. All the articles can be submitted online, then are submitted to the peer-review process. Final manuscripts of all accepted articles are also deposited into DOAJ (Directory of Open Access Journals), thus increasing their visibility and ease of use. In addition, RHC permits and encourages authors to post items submitted to the journal on personal websites or institutional repositories both prior to and after publication, providing adequate credits to the journal.

We hope that this choice is appreciated by authors and readers. We also hope we can have a part (even if small) in broadening the circulation and exchange of knowledge, not only in academic institutions, but also to all the interested professionals, to concerned journalists and policymakers.

What follows is a short interview with Peter Suber, an independent policy strategist for open access to research. More information about OA can be found at http://www.sherpa.ac.uk/links.htm. 
Peter Suber (http://bit.ly/suber) is Berkman Fellow at Harvard University, Senior Researcher at SPARC, the Open Access Project Director at Public Knowledge, and Research Professor of Philosophy at Earlham College. He conducts research, writing, consulting, and advocacy on open access and related topics.

Q: The aim of open access is to remove access barriers to publication. Don't you think that feebased model can be an obstacle for authors in less-developed countries?

A: Fee-based OA journals don't work as well as no-fee OA journals in fields and countries where most research is unfunded. But it's important to remember that the vast majority of OA journals $(70 \%)$ charge no publication fees at all. The percentage is even higher for OA journals published in developing countries. For example, nearly all the OA journals published in India are no-fee. It's equally important to remember that green $\mathrm{OA}$, or $\mathrm{OA}$ through repositories, is an inexpensive alternative to gold $\mathrm{OA}$, or OA through journals. More often than not, authors who publish in subscription-based journals have standing permission from the publisher to deposit their peer-reviewed manuscript in an OA repository. The percentage can approach $100 \%$ when universities and funding agencies require faculty and grantees to retain the right to authorize OA. For example, $100 \%$ of surveyed publishers accommodate the green OA mandate at the US National Institutes of Health.

Q: OA is compatible with peer review. Do you think that new approaches to peer review, such as open peer review, could arise from the $\mathrm{OA}$ movement?

A: OA is compatible with every kind of peer review, and does not presuppose or favor any particular kind. However, some new kinds of peer review, such as open review, presuppose OA. I welcome these experiments. But whether or not open review can be made to work, I hope that editors learn from the experiments. The OA movement is committed to the survival and integrity of peer review, but it's agnostic about the best from of peer review.

Q: In discussion about $\mathrm{OA}$ is usually stressed the role of Libraries and Institutions. What could be, in your opinion, the role of private publishers in this movement (if they have one)?

A: Publishers will always have a role in OA, if they want one. They can publish peer-reviewed OA journals, so-called gold OA, or they can allow authors to deposit their peer-reviewed manuscripts in

\section{We welcome your comments}

Reviews in Health Care welcomes your Letters to the Editor about editorials and articles that appear in RHC or issues relevant to healthcare. Address correspondence to s.maina@edizioniseed.it or submit your letter online at http://journals.edizioniseed.it/ index.php/rhc.
OA repositories, so-called green OA. The OA movement does not oppose publishers or publishing, only access barriers. Moreover, publishers themselves are not monolithic. Some provide OA themselves. Some - in fact, a majority - allow their authors to provide OA at will, and a growing number of others are experimenting with OA. OA has everything to gain and nothing to lose working with publishers who choose to work with OA. 


\section{Bacterial infections in patients with liver cirrhosis}

- Medical area. Infectivology; Hepathology.

- Why is a review on this topic needed? Bacterial infections represent a frequent complication of liver cirrhosis carrying a significantly greater risk of morbidity and mortality as compared to that observed in non-cirrhotic patients.

- Key message. The severity of liver disease represents the major clinical factor predisposing to bacterial infections, which are asymptomatic or paucisymptomatic at presentation in almost half of the cases. Beside antibiotics, it has been proposed the administration of human albumin to prevent the development of renal failure in patients with spontaneous bacterial peritonitis and, more recently, the use of hydrocortisone to treat cirrhotic patients with septic shock.

\section{Peripartum cardiomyopathy}

- Medical area. Gynaecology; Cardiology.

- Why is a review on this topic needed? The early diagnosis of peripartum cardiomyopathy and the institution of medical treatment for this disease are essential to avoid severe complications, including death. Nonetheless, currently its aetiology is not completely understood.

- Key message. Prolactin and its $16 \mathrm{kDa}$ metabolite seem to have a role in reducing cardiomyocite metabolic activity and contraction.

\section{Exercise stress testing in clinical practice}

- Medical area. Cardiology.

- Why is a review on this topic needed? Exercise stress testing is an important diagnostic tool for evaluating patient's cardiovascular performance.

- Key message. Exercise stress testing has an improved accuracy and is more clinically relevant when multiple risk parameters (ST-segment deviation, chest pain, exercise time, chronotropic competence, heart rate recovery, blood pressure recovery, ventricular arrhythmias) are incorporated into the final test result evaluation.

\section{The public health sector supply of modern contraceptives in rural Nigeria: an analysis of selection, forecasting and inventory control}

- Medical area. Public health; Contraception.

- Why is a review on this topic needed? Since public health facilities in rural Nigeria have been experiencing a long period of stock-outs and unavailability of modern contraceptives, recommendations are needed on how to improve the supply of modern contraceptives in this area.

- Key message. The current essential drug list should be reviewed in order to include injectables for use in primary facilities, strengthen the current forecasting, data reporting and inventory control system. 